\title{
AS TRAJETÓRIAS DE FORMAÇÃO DE PROFESSORES NO MUNICÍPIO DE NAVIRAÍ (1960 - 2012)
}

\author{
The training training of teachers in the municipality of Naviraí (1960 - 2012)
}

Las trajetorias de formación de profesores en el municipio de Naviraí (1960 - 2012)

\author{
Larissa Wayhs Trien Montiel* \\ Luciene Clea da Silva* \\ Adriana Horta de Faria* \\ Giseli Tavares de Souza Rodrigues*
}

\begin{abstract}
Resumo
A finalidade do estudo foi caracterizar a trajetória de formação de professores do município de Naviraí/MS entre os anos de 1960 a 2012. A fim de compreender aspectos acerca da história da formação docente no Brasil, pontuando questões sobre a formação de professores em Mato Grosso uno e constatar o processo vivido pelos professores que iniciaram suas carreiras como professores leigos e foram em busca da habilitação para o magistério e a conquista da formação em nível superior. Optamos por discutir e apresentar a formação docente por meio dos relatos orais da história vivida pelos professores. Para tanto, adotamos como proposta metodológica a realização de entrevistas semiestruturadas embasadas na História Oral Temática. Os relatos esclarecem que a formação, durante a sua trajetória profissional em projetos de formação ou cursos ofertados pelo Ministério da Educação, possibilitaram aperfeiçoamento profissional e a continuidade da atuação desses professores. E houve uma tentativa de firmar posições de poder em novas configurações que se ajustam aos contextos sociais organizados. Assim, coube aos professores buscar a formação superior para garantir o status de poder enquanto profissionais da educação e o respeito pelos seus pares.
\end{abstract}

\footnotetext{
* Doutora em Educação na linha de História Memória e Sociedade na Universidade Federal da Grande Dourados (UFGD). Atualmente é professora do quadro efetivo da Fundação Universidade Federal de Mato Grosso do Sul (UFMS/campus Naviraí), pesquisadora do Grupo de Estudos e Pesquisa em Prática Educativa e Tecnologia Educacional (GEPPETE). Líder da Linha de Pesquisa Práticas Educativas e Formação Docente. Integrante do Grupo de Pesquisa Educação e Processo Civilizador (GPEPC). Email: larissa.montiel@ufms.br.

* Doutoranda em Educação pela Universidade Federal da Grande Dourados (UFGD) na Linha de pesquisa em História da Educação, Memória e Sociedade. Atualmente é professora da Universidade Federal de Mato Grasso do Sul (UFMS/campus de Ponta Porã). Líder do Grupo de Estudo e Pesquisa em Educação Fronteiriça (GEPEF). Integrante do Grupo de Pesquisa Educação e Processo Civilizador (GPEPC). Email: lugiraldelli@gmail.com.

* Doutoranda em Educação pela Universidade Federal da Grande Dourados (UFGD) na linha de História da Educação, Memória e Sociedade. Professora da rede básica de educação no município de Naviraí/MS. Professora substituta na Universidade Federal de Mato Grosso do Sul. Email: profadrianahortadefaria@gmail.com

* Mestra em Educação Educação pela Universidade Federal da Grande Dourados (UFGD) na linha de História da Educação, Memória e Sociedade. Atualmente é professora da Educação Infantil. Email: giselits2010@hotmail.com
} 
PALAVRAS-CHAVE: Histórias de docência. Projetos de Formação História Oral. Mato Grosso do Sul.

\begin{abstract}
The purpose of the study was to characterize the trajectory of teacher education in the municipality of Naviraí / MS between the years 1960 to 2012. In order to understand aspects about the history of teacher training in Brazil, punctuating questions about teacher training in Mato Grosso one and to verify the process experienced by teachers who started their careers as lay teachers and were in search of qualification for teaching and achievement training at a higher education. We chose to discuss and present teacher education through oral reports of the history experienced by teachers. To this end, we adopted as a methodological proposal the realization of semi-structured interviews based on Thematic Oral History. The reports clarify that training during their professional trajectory in training projects or courses offered by the Ministry of Education enabled professional improvement and the continuity of the performance of these teachers. And there was an attempt to establish positions of power in new configurations that adjust to the organized social contexts. Thus, it was up to teachers to seek higher education to ensure the status of power as education professionals and respect for their peers.
\end{abstract}

KEYWORDS: Teaching stories. Oral History Training Projects. Mato Grosso do Sul.

\title{
Resumen
}

La finalidad do estudio fue la caracteristica y trajetoria de formación de los profesores del Municipio de Naviraí/MS entre los años de 1960 a 2012. Para compreender los aspectos acerca de la historia da formación docente en Brazil apuntando questiones sobre los profesores en Mato Grosso y constatar lo proceso vivido por los profesores que comenzaran suas carreras como profesores laicos y fueran en busqueda de habilidades para el magisterio e la vitoria da formación en nivel superior. La opción fue discutir y presentar la formación docente por medio dos relatos orales da historia vivida por los profesores. Para todo, pusemos como propuesta metodologica a realización de entrevista semi-estructurada embasadas en la Historia Orale Tematico. Los relatos clarean que la formación durante la trajetória profisionale en proyecto de frmación o cursos ofrecidos pelo Ministerio da Educación habilitaron mejora profesional e la comunidad de atuación deses profesores . y tuvuerán intento de buscar firmar posiciones de poder in nuevas configuracionesque se adequan a los contextos sociales organizados. Así, coube a los profesores la busqueda por la formación superior para la garantia de status de poder encuanto profisionales da educación e o respeto por sus parejas.

PALABRAS CLAVE: Historia de la docencia. Proyecto de Formación Historia Orale. Mato Grosso do Sul.

\section{INTRODUÇÃO}

A finalidade deste estudo foi caracterizar a trajetória de formação de professores do município de Naviraí/MS entre os anos de 1960 a 2012. Sendo assim, apresentamos aspectos acerca da história da formação docente no Brasil, pontuamos questões sobre a 
formação de professores em Mato Grosso uno ${ }^{1}$, buscando constatar o processo vivido pelos participantes da pesquisa na busca pela habilitação para o magistério e a conquista da formação em nível superior. Este artigo apresenta a trajetória dos professores João Batista Venâncio e Maria da Cruz dos Santos, que são profissionais que se formaram e construíram a carreira docente no município de Naviraí/MS.

O professor Venâncio é oriundo de Ribeirão Claro, no norte do Paraná, veio para Naviraí ainda jovem juntamente com a sua família, no ano de 1968. Venâncio tem 66 anos, formou-se em magistério e cursou Pedagogia. Atuou na profissão docente por 38 anos durante os anos de 1964 a 2002 . Hoje, o professor encontra-se aposentado. Maria também não é naviraiense, pois nasceu em Nova Granada, São Paulo, porém desde os 6 anos de idade reside em Naviraí, quando seus pais se mudaram para o município em 1966. A professora tem 57 anos, possui formação em magistério, Normal Superior e Pedagogia. Trabalhou 30 anos na docência entre os anos de 1982 a 2012. Atualmente, é aposentada.

Justificamos que o recorte temporal determinado para a pesquisa parte do ano de 1960, considerando o período do início da carreira dos professores e, 2012 a aposentadoria e o término do tempo dos docentes na escola. Compreendemos assim, que as relações de interdependência que se estabeleceram no percurso da consolidação da profissão determinaram a formação profissional, pessoal e social dos envolvidos. Esse processo regulatório de coerção e auto coerção acontece por ações planejadas e também não planejadas, o que Elias (2006) indica ser um processo cego, pois:

\begin{abstract}
As variáveis se dão em modelos que exprimem diferentes tipos de regulação do comportamento, nos tipos de coação externa e auto coação. Tais elementos existem em todos os grupos sociais e incidem num processo de individualização permitindo que o sujeito seja educado para ser parte do grupo a partir dos comportamentos internalizados, em um processo que passa de uma geração para outra (SARAT, 2011, p. 122).
\end{abstract}

A fim de compreender a história como um processo, nesse caso por meio da trajetória dos indivíduos, Thompson (1981) contribui admitindo ser muito difícil tentar teorizar ou formular a pesquisa sem a empiria, visto que um processo histórico é indeterminado e permanece sujeito a certas pressões. Dessa maneira:

Em última análise, a lógica do processo só pode ser descrita em termos de análise histórica; nenhuma analogia derivada de qualquer outra área pode ter mais que um valor limitado, ilustrativo e metafórico [...] a "história" só pode ser teorizada em termos de suas propriedades peculiares (THOMPSON, 1981, p. 97).

\footnotetext{
${ }^{1}$ A colonização desses locais ocorreu ainda quando o estado de Mato Grosso (MT) era unificado, pois o estado de Mato Grosso do Sul (MS) só foi criado posteriormente, com a divisão ocorrida por meio da Lei Federal Complementar $\mathrm{n}^{\circ}$ 31, de 11 de outubro de 1977, que desmembrou o antigo Mato Grosso (BRASIL, 1977). Optamos, neste trabalho, por usar a denominação de "Mato Grosso uno", tendo em vista que a história dos professores começa antes da divisão do estado. Entendemos, contudo, que, ao recuperar essas fontes e documentos, a presente pesquisa também contribuirá com a história da educação do Mato Grosso do Sul.
} 
Diante disso, podemos afirmar que compreendemos os indivíduos em suas figurações, o que "significa dizer que o ponto de partida de toda investigação sociológica é uma pluralidade de indivíduos, os quais, de um modo ou de outro, são interdependentes" (ELIAS, 2001, p. 184), nas relações que estabelecem uns com os outros. Para tanto, os indivíduos existem em "figurações e só podem ser entendidos dessa forma por meio das relações de interdependência entre os indivíduos que se agrupam em figurações específicas" (ELIAS, 2006, p. 26). Assim, as relações de interdependência entre indivíduo e sociedade se constituem ao longo do processo social e histórico formando redes de relações.

Precisamos compreender que as figurações não são fixas, como afirma Landini (2005, p. 06):

Estão em continuamente em fluxo, passando por mudanças de ordens diversas, algumas rápidas e efêmeras e outras mais lentas e profundas e os processos que ocorrem nessas figurações possuem dinâmicas próprias, dinâmicas nas quais razões individuais possuem um papel, mas não podem de forma alguma se reduzidas a essas razões [...] o termo figuração pode ser definido como redes formadas por seres humanos interdependentes, como mudanças assimétricas em uma balança de poder, enfatizando o caráter processual e dinâmico das redes criadas por indivíduos.

Por meio do pensamento de Eliasiano (2006) demonstra que se podem reconstruir grandes processos históricos a partir de objetos aparentemente menores e sugere a possibilidade de observarmos as figurações sociais de grande escala, por meio da análise das tensões que estruturam um micromundo social (o lugar de uma profissão). Significa dizer que a constituição do indivíduo profissional da educação, como professor, resulta das diferentes figurações em que estão imersos nas redes de interdependência. Nessa perspectiva, as pessoas modelam suas ideias a partir de todas as experiências que tiveram no interior de seu próprio grupo e o docente está vinculado à formação sócio histórica e cultural do seu meio.

O convívio dos seres humanos em sociedade tem sempre, segundo Elias (2006), mesmo no caos, na desintegração, na maior desordem social, uma forma absolutamente determinada. Sendo assim, é:

Incorreto tentar explicar eventos sociais simplesmente em função das ações humanas intencionais, os processos são engendrados pelo entrelaçar de ações intencionais e planos de muitas pessoas, mas nenhuma delas realmente os planejou ou desejou individualmente (LANDINI, 2005, p. 07).

A formação de um indivíduo pode ser entendida como um processo que o acompanha por toda a vida e está envolvida em diferentes dimensões, como a relação com a família de origem, o currículo escolar, as etapas oficiais da formação, o espaço profissional, o prolongamento universitário, as origens culturais e as funções sociais. No caso de professores, é um processo contínuo de reflexão autônoma e contribui para o enriquecimento dos saberes, dos valores pessoais e dos conhecimentos teórico-práticos, compreendendo a diversidade dos "formatos" de aprendizagem como desenvolvimento profissional (JOSSO, 2010; NÓVOA, 2000). 
Nesse sentido, Norbert Elias aponta a necessidade de examinar o percurso pelo qual as profissões se constituem no interior das sociedades, pois elas só podem ser entendidas a partir do contexto social e histórico em que são criadas e a profissionalização de uma atividade ocorre quando há "[...] mudança de uma comunidade inteira que cria as condições para o surgimento de uma nova ocupação e determina o curso de seu desenvolvimento" (ELIAS, 2006, p. 89).

Ao ser constituída uma profissão, ela passa a exigir conhecimentos específicos aliados a habilidades adquiridas, ou seja, é imprescindível a inferência teórica e não apenas a prática para se aprender o ofício. Tais conhecimentos devem ser testados por instituições autorizadas, outorgando assim a autoridade para a execução da atividade (GEBARA, 2012). No caso da constituição histórica da profissão do magistério, a origem está nas chamadas "escolas normais" e de formação de professores.

A metodologia utilizada foi a História Oral Temática que privilegia e está atrelada a um conteúdo exclusivo, proporcionando o testemunho e relatos dos indivíduos e a retomada de suas experiências de vida pessoal ou profissional. A "[...] História Oral Temática aborda questões externas, objetivas, factuais, temáticas [...]" (MEIHY, 1994, p. 57, sic), objetiva ouvir fatos ocultos e dá oportunidade para o indivíduo falar sobre sua história, permitindo o contato direto do pesquisador com sua fonte de estudo. A História Oral é vista como "[...] um método de pesquisa (histórica, antropológica, sociológica etc.) que privilegia a realização de entrevista com pessoas que participaram de, ou testemunharam, acontecimentos, conjunturas, visões de mundo, [...]" (ALBERTI, 2013, p. 24). Foi usado o método chamado de entrevista e, por meio dele, tronou-se possível o contato com as experiências, lembranças e memórias dos professores pesquisados que foram fundamentais para constituir todo o arcabouço empírico deste artigo.

Utilizamos como fonte os relatos das experiências de um passado recente, trilhando os caminhos percorridos e ressignificados pelos entrevistados. O lembrar possibilita enriquecer as vivências, dando cor, profundidade e significado, armazenando um pouco de tudo que foi vivido e experimentado. Dados, sensações, sentimentos e saberes estão guardados, segundo um código de acesso próprio e quase desconhecido do indivíduo que lembra. Perscrutamos assim, que esses indivíduos vivenciaram esse processo de mudança da sua trajetória de vida, por meio de suas formações durante sua carreira docente.

Para tanto, optamos por apresentar o artigo da seguinte forma: indicando os apontamentos sobre a história da formação docente no Brasil, na sequência apresentamos como ocorreu a formação de professores em Mato Grosso uno, em seguida discutimos o processo de habilitação para o exercício do magistério por meio dos projetos LOGOS I e LOGOS II e finalizamos com a contextualização sobre a Formação docente a partir dos cursos Normal Superior e Pedagogia que fizeram parte da trajetória dos professores pesquisados. Nesse sentido, o texto procurou indicar como as escolhas de vida de indivíduos professores contribuíram para esclarecer a trajetória de uma profissão.

\section{Apontamentos sobre a história da formação docente no Brasil}


As escolas normais no Brasil foram criadas ainda no período imperial, cumprindo o papel desse lugar específico de formação para qualificar os professores no intuito de ampliar a escolaridade elementar. As escolas normais eram fundamentais à formação do professor. Segundo Tanuri (2000), as primeiras instituições foram "[...] destinadas exclusivamente aos elementos do sexo masculino, simplesmente excluindose as mulheres". Embora houvesse necessidade de escolas de formação de professores, "[...] as poucas escolas normais do Brasil, pautadas nos moldes de medíocres escolas primárias, não foram além de ensaios rudimentares e malsucedidos" (TANURI, 2000, p. $65)$.

Posteriormente, em 1879, pelo Decreto $\mathrm{n}^{\mathrm{o}} 7.247$, o Poder Central, por meio da Reforma Leôncio de Carvalho (BRASIL, 1879), estabeleceu a necessidade da submissão dos alunos a exames de avaliação para a aprovação no curso das escolas normais. No final do império havia poucas escolas normais públicas e, em algumas províncias, algumas iniciativas contribuíram para o desenvolvimento das escolas. Dentre elas, Tanuri (2000, p. 17) cita: "Almeida de Oliveira (18/9/1882), Rui Barbosa (12/9/1882) e Cunha Leitão (24/8/1886). Esses projetos evidenciam que o papel das escolas normais no desenvolvimento quantitativo e qualitativo do ensino primário começava a ser reconhecido".

Em finais do século XIX e início do século XX, os governantes do estado de São Paulo desenvolveram um novo modelo de administração educacional, inspirados pelas filosofias cientificistas, que influenciaram os sistemas de outros estados, inclusive o Mato Grosso uno. Diversas modalidades do curso normal foram implantadas e reformuladas. $\mathrm{O}$ objetivo esteve em pautar os ensinos nas bases científicas, contemplando questões teóricas e práticas (TANURI, 2000).

Em finais do século XX, precisamente em 1971, com a promulgação da Lei Federal $n^{\circ} 5.692$ (BRASIL, 1971), em plena vigência da ditadura militar, ocorreram reformas no âmbito da educação e a educação técnica passou a ser prioridade. A escola normal passa a ser chamada de "habilitação para o magistério", tornando-se um curso de nível médio. Posteriormente, o mais recente reconhecimento de necessidade de formação necessária para a atuação docente está na Lei de Diretrizes e Bases da Educação Nacional - LDBEN em vigência (Lei Federal no 9.394/1996), que determina “[...] a formação de docentes para atuar na educação básica far-se-á em nível superior, em curso de licenciatura, de graduação plena, em universidades e institutos superiores de educação [...]" (BRASIL, 1996).

Tal legislação marca o fim da formação em escolas normais e magistério, passando para as instituições de nível superior, embora em alguns casos ainda mantenham uma formação em nível médio para suprir demandas específicas de algumas regiões $^{2}$.

\section{Formação de professores em Mato Grosso uno}

\footnotetext{
${ }^{2}$ Houve ainda a institucionalização dos Institutos Superiores de Educação - ISEs e de seus cursos superiores a partir da promulgação da Lei de Diretrizes e Bases da Educação Nacional (Lei Federal $\mathbf{n}^{\circ}$ 9394/1996), além de mudanças ocorridas na formação docente a partir da instauração das Diretrizes Curriculares Nacionais para o Curso de Pedagogia - DCNs-Pedagogia (Parecer CNE/CP n ${ }^{\circ}$ 5, de 13 de dezembro de 2005, e instituídas pela Resolução CNE/CP n ${ }^{\circ}$, de 15 de maio de 2006).
} 
É interessante notar que, na província de Mato Grosso, a primeira iniciativa de implantação da escola normal foi instituída pela Lei Provincial $\mathrm{n}^{\circ} 8$, de 5 de maio de 1837. Sua instalação ocorreu em 1840 e logo é desativada em 1844. Depois a província ficou por 30 anos sem instituições para a formação de professores, até que, em 3 de fevereiro de 1874, em Cuiabá é inaugurado o Curso Normal, que em 1876 passa a atender as mulheres e foi substituído pelo Liceu de Línguas e Ciências por força da Lei $\mathrm{n}^{\circ}$ 536, de 3 de dezembro de 1879. Esse liceu foi sucedido pelo Externato do Sexo Feminino, para a formação de mestras, este último criado com a reforma de 1889 e anexado ao Curso de Preparatórios. Mesmo assim, contudo, a formação de professores ainda era um aspecto deficiente (CASTANHA, 2007).

No período da república, diante dos ideais de uma "nova civilização", mais moderna, houve iniciativas na educação como a criação de grupos escolares para a formação de indivíduos que colocassem em prática os preceitos organizacionais. Nos primeiros anos da nova organização política, porém, o "[...] sistema educacional de Mato Grosso uno era simplesmente caótico, caracterizado pela escassez de professores e pela precariedade de material e estrutura física" (BRAZIL, et al., 2015, p. 191).

Em 1908 o então presidente do estado, Coronel Pedro Celestino Correa da Costa, viabilizou duas iniciativas para a melhoria da educação, sendo a criação das escolas primárias nas cidades mais prósperas do estado e a escola normal da capital. A educação possuía características que acompanhavam o desenvolvimento da região, como a influência do coronelismo, que decidia quem era contratado para ser professor, bem como a abertura e fechamento das escolas (RODRÍGUEZ; OLIVEIRA, 2008; BRAZIL et al., 2015).

As professoras formadas em escola normal eram vistas como verdadeiras regeneradoras da pátria, pois pautavam a prática no que existia de mais moderno no processo pedagógico. De acordo com Rodriguez e Oliveira (2008, p. 4), "no caso de Mato Grosso, apesar desse ambiente modernizante e 'progressista', o Ensino Normal não encontrou um espaço para se expandir".

Enquanto no Brasil os pioneiros da Escola Nova buscavam introduzir novos padrões pedagógicos, em Mato Grosso uno ainda se buscava a difusão do ensino primário e a formação dos professores. Por volta dos anos 30 do século XX, existiam dois cursos de ensino normal, um em Cuiabá e outro em Campo Grande. Na chamada Era Vargas (1930-1945), o governador Júlio Müller (1937-1945) incorporou a Escola Normal Pedro Celestino ao Liceu Cuiabano, introduzindo apenas o curso para o magistério primário. A alegação era o número de normalistas necessárias para atender às escolas primarias de todo o estado (RODRÍGUEZ, OLIVEIRA, 2008).

A região sul do estado, a partir da construção da estrada de ferro (Corumbá Campo Grande), em 1914, e a imigração de árabes, japoneses, espanhóis, portugueses e italianos, além da imigração originária das diversas regiões nacionais, começou a se urbanizar e, com o aumento da população, houve a necessidade da expansão escolar. Então, para atender à deficiência de professores na região, instalou-se a Escola Normal de Campo Grande, em 21 de abril de 1930 (RODRÍGUEZ; OLIVEIRA, 2008).

Em 1940, a escola normal de Campo Grande foi fechada. A partir disso, a escola normal experimentou um processo de reabilitação e expansão, principalmente no setor 
confessional. Em 1948, a escola normal de Campo Grande foi reaberta e recebeu o nome de Escola Normal Joaquim Murtinho. Seus cursos sofreram reformulações e se mantiveram até 1973. Havia ainda outras escolas normais nos centros urbanos maiores.

Nesse ínterim, no entanto, o sul do estado vivia uma figuração específica. A exploração da erva-mate foi fundamental para o povoamento e o desenvolvimento da região. Desde o fim da época imperial e adentrando o período da república, Thomas Laranjeira comandava a extração ervateira da região. A mão de obra era composta por migrantes oriundos principalmente do Rio Grande do Sul e pelos naturais da terra (indígenas). A maioria dos trabalhadores vivia nas fazendas e as escolas estavam nos centros urbanos. A instrução escolar não fazia parte da vida dos filhos dos trabalhadores, pois mesmo as crianças também compunham a força de trabalho (BRAZIL, et al., 2015).

No extremo sul do estado, no município de Caarapó, no início do século XX, as famílias de melhores posses enviavam seus filhos para estudar nas cidades de origem de seus pais. A partir de 1920, para os filhos dos trabalhadores foram instaladas, nas fazendas, as escolas provisórias, e as meninas raramente estudavam e, quando podiam, aprendiam somente as prendas domésticas. Os professores eram homens ambulantes ou andarilhos, pessoas que se instalavam por determinados períodos na região e que se propunham a lecionar para grupos de crianças, mas sem compromisso institucional (BRAZIL et al., 2015).

Nesse cenário, também alguns voluntários se ocupavam de lecionar, entre eles as mulheres migrantes e imigrantes, geralmente esposas dos fazendeiros ou de funcionários que tinham algum conhecimento de leitura, escrita e aritmética. A maioria das crianças não participava nem mesmo da educação rudimentar que era oferecida.

Sobre a formação de professores no período que abrange os primeiros anos da trajetória dos professores Venâncio e Maria, convém lembrar que a Lei Federal $\mathrm{n}^{\mathrm{o}}$ 5.692/1971 previa que o mínimo de formação para o exercício do magistério que o professor das quatro primeiras series do $1^{\circ}$ grau deveria ter a habilitação específica de $2^{\circ}$ grau, que equivaleria ao curso magistério ou o normal, conforme estipula o artigo 30:

Exigir-se-á como formação mínima para o exercício do magistério:

a) no ensino de $1^{\circ}$ grau, da $1^{\mathrm{a}}$ à $4^{\mathrm{a}}$ séries, habilitação específica de $2^{\circ}$ grau;

b) no ensino de $1^{\circ}$ grau, da $1^{\mathrm{a}}$ à $8^{\mathrm{a}}$ séries, habilitação específica de grau superior, ao nível de graduação, representada por licenciatura de $1^{\circ}$ grau obtida em curso de curta duração;

c) em todo o ensino de $1^{\circ}$ e $2^{\circ}$ graus, habilitação específica obtida em curso superior de graduação correspondente à licenciatura plena. (BRASIL, 1971).

A habilitação específica para o magistério - HEM, estipulada no período, passa a ser obrigatória e essa reforma educacional foi reforçada pelo aspecto tecnicista, voltado para a formação de mão de obra para suprir as necessidades do mercado de trabalho. Nesse contexto, a "Escola Normal" perde a sua identidade de escola e de curso, e a formação de normalista torna-se apenas uma das variadas possibilidades de habilitações profissionais para os professores. Segundo Tanuri: "[...] desapareciam os institutos de educação e a formação de especialistas e professores para o curso normal passou a ser feita exclusivamente nos cursos de Pedagogia" (TANURI, 2000, p. 80). 
Essa Lei Federal $n^{\circ}$ 5.692/1971 não contemplou, no entanto, a formação específica para professores da área rural. Somente citava no artigo 29 que a preparação para esses indivíduos deveria "[...] estar de acordo com as diferenças culturais de cada região do País" (BRASIL, 1971). Assim, a formação dos professores entrevistados nesta pesquisa ocorreu por meio de cursos de capacitação. Somente por volta da década de 1980 eles tiveram a habilitação específica para o magistério e, mais tarde, a formação em nível superior. No início da profissão, esses docentes eram leigos e precisavam relacionar conhecimentos científicos e cotidianos com a preservação da identidade local, a relação com a terra, uma escolarização fundada em diferentes formas de compartilhar saberes e culturas, indicando, assim, uma educação inserida e voltada à realidade concreta vivenciada com as crianças.

Entre os cursos de capacitação oferecidos pela prefeitura de Naviraí, o professor Venâncio esteve presente no "Curso Moderno de Orientação Pedagógica" em 1970, e "Curso de Aperfeiçoamento Pedagógico" em 1971. Havia ainda iniciativas dos donos das fazendas da região, que construíam escolas rurais em parceria com o município nas quais atuavam professores leigos. Os cursos oferecidos pela Secretaria de Educação e Cultura de Naviraí, aconteciam em períodos de férias escolares e não habilitavam para o magistério, somente promoviam capacitação para a continuidade da docência nessas áreas.

$\mathrm{Na}$ década de 1980 em diante os cursos de capacitação continuaram acontecendo, foi quando a professora Maria teve a oportunidade de participar de vários deles, tanto no município como em Campo Grande, enviada pela Secretaria de Educação e Cultura. Dentre os cursos que ela participou estava o curso de "Metodologia Aplicada a Educação" em 1985, "Curso de Artes Plásticas" em 1986 e a "Capacitação para professores de Educação Infantil" realizado em 1996, entre outros. No próximo item indicamos como ocorria a formação de professores leigos nas áreas rurais.

\section{O processo de habilitação de professores leigos para o exercício do magistério: Projetos LOGOS I e LOGOS II}

Para a habilitação dos professores leigos das áreas rurais, nas décadas de 1960, 1970 e 1980, foram criados, a partir do Programa de Aperfeiçoamento do Magistério Primário (PAMP), o Centro de Treinamento do Magistério em Cuiabá, o Curso de Magistério Rural e os projetos LOGOS I e II. Durante os anos 1980, o destaque para a formação de professores leigos ${ }^{3}$ foram os Projetos LOGOS I e II. O projeto Logos I foi uma experiência inicial. Ele visava apontar uma metodologia, mas tinha limitação orçamentária e poucos recursos humanos envolvidos, contudo os resultados foram encorajadores e, em seguida, foi criado o LOGOS II.

Em Naviraí, em 1980 até inicio de 1990, havia professores leigos atuando principalmente nas áreas rurais, segundo a professora Maria existia "muitos professores sem formação nenhuma, a gente participava de muitos cursos de capacitação, mas uns

\footnotetext{
${ }^{3}$ Nesse período, entedia-se que "professor leigo" era todo docente que estava atuando em sala de aula e não tinha a habilitação de acordo com o artigo 30 da Lei de Diretrizes e Bases - LDB da época (Lei Federal n $\left.{ }^{\circ} 5.692 / 1971\right)$.
} 
tinham o magistério outros não, e trabalhavam assim mesmo, por que precisava atender as crianças" (MARIA, 2018).

Desse modo, o projeto LOGOS I no início de 1980 funcionava em Dourados e muitos professores de Naviraí eram enviados pela Secretaria de Educação e Cultura para realizar o curso nos finais de semana. Conforme Rodrigues (2018), somente em meados dessa década foi implantado no município de Naviraí, agora já como parte do estado de Mato Grosso do Sul, o projeto LOGOS II para aqueles que ainda não tinham concluído o magistério. Foi assim que Venâncio e Maria cursaram o projeto LOGOS II, a professora não teve nenhuma experiência formativa na primeira fase desse projeto que foi o LOGOS I, mas na segunda fase, sendo o LOGOS II, ela pôde participar porque o referido curso passou a ser desenvolvido em Naviraí. A professora Maria também realizou outros cursos de habilitação profissional que serão abordados mais adiante.

O LOGOS II surgiu principalmente nos locais em que o contingente de professores leigos fosse representativo. Segundo Arruda (2011, p. 118), o projeto LOGOS teve características próprias da educação tecnicista e das propostas de educação do período em questão:

O Projeto Logos II foi uma típica iniciativa educacional inspirada nas concepções tecnicistas de educação e de mundo na forma de Educação Supletiva. De fato, na década de 1970, a carência de professores com formação técnica específica em nível de $2^{\circ}$ grau, ou magistério, era uma realidade que caracterizava as escolas primárias dos municípios interioranos do Brasil, especialmente nos estados menos desenvolvidos, ou mais pobres. Nas escolas "multisseriadas" das zonas rurais essa era a realidade, constituindo-se exceção a presença em sala de aula de uma professora, ou professor, habilitado no magistério.

O curso funcionava como supletivo ${ }^{4}$ e estava organizado em módulos por disciplinas. Tinha uma duração de 28 a 30 meses até a sua conclusão. As aulas aconteciam em finais de semana, mais uma vez exigindo dos profissionais sacrifícios das horas de descanso e das atividades pessoais e familiares. Pereira (2015) aponta o motivo das aulas acontecerem geralmente aos sábados e domingos, apontando os interesses institucionais:

É clara a grande preocupação do MEC de que os professores não deixassem de atuar. Primeiro, porque eles representavam mais de $70 \%$ do número total e também porque não havia professorado formado para atender a demanda escolar. Reside aí a grande necessidade de formar os professores leigos de forma rápida e eficiente (PEREIRA, 2015, p. 39).

Tais cursos possuíam uma carga horária alta e oferecida fora do tempo de trabalho, principalmente em finais de semana, o que os tornava uma tarefa de difícil execução. O professor Venâncio (2017) assim se expressou: "Era um curso pesado". Ao total, a carga horária podia chegar a 3.480 horas, e o aluno ainda deveria cumprir o estágio supervisionado. Maria também falou sobre sua experiência no LOGOS II, como destacou: "[...] era o magistério em módulos acontecia nos finais de semana e ia até a noite. Mas foi um curso muito bom e a professora era maravilhosa. Terminei em 1987" (MARIA, 2018).

\footnotetext{
${ }^{4}$ Cursos na modalidade a distância e com encontros presenciais.
} 
Entretanto, o projeto LOGOS II foi significativo na formação de docentes não titulados, como expressaram os professores Venâncio e Maria. O "[...] projeto LOGOS II foi muito importante para a formação de professores em nosso país no momento em que foi realizado. O mesmo atingiu grandes proporções e, ainda que dentro de suas limitações, propiciou a certificação de milhares de professores leigos" (PEREIRA, 2015, p. 133). Nessa direção, no mesmo período, houve em Naviraí o curso Normal de Férias na escola Estadual Juracy Alves Cardoso, o qual formou apenas uma turma com duração de 3 anos e, por conseguinte surgiu o Centro de Formação e Aperfeiçoamento do Magistério - CEFAM.

Tais projetos e cursos possibilitaram aperfeiçoamento profissional e a continuidade da atuação desses professores. De maneira que podemos dizer que a centralização da formação para a habilitação do profissional aponta o processo de transformações estruturais na atividade docente, especialmente na atividade representada por esses indivíduos (ELIAS, 2006).

\section{Formação docente a partir dos cursos Normal Superior e Pedagogia}

Os professores Venâncio e Maria, não encerraram suas trajetórias de formação no projeto LOGOS II, eles continuaram em busca de aperfeiçoamento de suas carreiras. O professor Venâncio cursou o ensino superior em faculdade particular. Primeiro tentou o vestibular para o Curso de Matemática que era oferecido pela Universidade Estadual de Mato Grosso do Sul - UEMS, mas não esperou ser convocado e foi estudar Pedagogia no centro de Faculdades Integradas de Naviraí - FINAV ${ }^{5}$. O professor se formou no ano de 2000 e se aposentou em 2002. Ele narra:

Como eu nunca gostei de estudar matemática, de ensinar, sim, mas estudar matemática.... Apareceu vestibular para Pedagogia, eu fiz. Na minha redação, eu tirei 9.8. O tema era ecologia versus economia. E aí o primeiro ano eu ganhei a bolsa de estudo e esse um ano que eu não paguei eu guardei o dinheiro para a formatura. (VENÂNCIO, 2017).

O professor obteve bolsa de estudos e a faculdade ficava na cidade em que morava, o que facilitava a sua permanência. Venâncio fala sobre a sua percepção sobre o ensino superior: "Cada dia é um dia diferente e a gente vai aprendendo cada dia mais e quando eu entrei na faculdade e eu comecei a estudar, pensava: "Meu Deus, o que é isso? "O mundo é diferente..." (VENÂNCIO, 2017). Mesmo com 31 anos de experiência, o professor voltou a estudar e, nesse processo, percebe-se o significado de ensinar e aprender, que são indissociáveis e merecem tempos para a reflexão, para o questionamento, para a problematização, a pesquisa, a discussão e a avaliação.

Nessa perspectiva, Maria também seguiu o processo formativo. Quando a FINAV chegou a Naviraí, ela tinha terminado o magistério em 1987, mas já atuava desde 1982 ao iniciar como leiga em turmas rurais multisseriadas. O salário era pouco e Maria não pôde cursar Pedagogia logo que a faculdade surgiu e, somente em 1999 conseguiu fazer o referido curso, e finalizou em 2001. Um ano após ingressar na

\footnotetext{
5 Faculdades Integradas de Naviraí - FINAV - o primeiro centro privado de formação docente no município - foi trazido pelo prefeito Simplício Vieira de Souza Nego em 1987 em parceria com a Sra. Ively Monteiro, que era dona de uma faculdade em Fátima do Sul/MS (MARIA, 2018).
} 
Pedagogia, ela havia começado o Normal Superior em Mundo Novo/MS, na Universidade Estadual de Mato Grosso do Sul - UEMS, o qual encerrou em 2003.

A professora apontou que levar os dois cursos e trabalhar ao mesmo tempo foi difícil, era corrido lecionar e estudar, mas era preciso ter a formação superior. Assim relatou que: "Estudar fora, e trabalhar o dia todo era muito puxado para mim. Mas eu sabia o quanto era importante ter essa formação para eu seguir na profissão. Eu gostava de estudar, mas ir para Mundo Novo ${ }^{6}$ era complicado” (MARIA, 2018).

Nota-se, a partir dos argumentos de Maria que, de fato, a aquisição da formação superior ocorre quando um professor tem a oportunidade de construir e reconstruir os seus saberes em confronto com as suas vivências cotidianas. Desse modo, a professora Maria teve uma experiência de 30 anos na profissão docente. Ela se aposentou em 2012, aos 52 anos, quando uma depressão a afastou da docência. Segundo Elias (2006), os embates que são travados no interior das profissões, podem sugerir que há uma tentativa de firmar posições de poder em novas configurações que se ajustam aos contextos sociais organizados. Assim, coube aos professores buscar a formação superior para garantir o status de poder enquanto profissionais da educação e o respeito pelos seus pares.

\section{CONSIDERAÇÕES FINAIS}

A concepção de que, ao investir na formação, gera uma situação profissional bem-sucedida e uma estabilidade financeira, foi um mecanismo para que esses indivíduos buscassem a formação superior. Percebemos, porém, que eles tinham ciência de que a devida preparação podia ser um fator determinante na melhoria da qualidade da educação e da trajetória de vida deles. Dessa forma, todos participaram de cursos de treinamento, de habilitação para o magistério e de formação em nível superior. A formação de professores foi pautada em uma relação entre os saberes da vida, ou do cotidiano, e um processo contínuo de desenvolvimento pessoal e profissional.

Assim, podemos considerar que a expressão "profissionalização docente" referese ao movimento dos professores para atingir o status de valorização na profissão. Ou seria o lugar que cada indivíduo ocupa nas relações que se estabelecem no seu lugar profissional, como afirma Elias (2006): a figuração dos profissionais se altera a partir do momento em que o Pêndulo da balança de poder tende a garantir um novo lugar social. Para tanto, foi feito um grande esforço por parte dos professores Venâncio e Maria para que o trabalho docente realizado por eles, em um primeiro momento de forma leiga, se tornasse um trabalho titulado e reconhecido, ou seja, compreendido como profissão.

\section{REFERÊNCIAS}

ARRUDA, E. B. Uma tentativa de reinvenção da escola pública como instrumento de emancipação dos trabalhadores - o caso do NEP de Colíder. Dissertação (Mestrado em Educação). UFMT - Universidade Federal de Mato Grosso, 2011.

\footnotetext{
${ }^{6}$ Mundo Novo é uma cidade vizinha a Naviraí e divisa com o estado do Paraná, fica distante cerca de $108 \mathrm{Km}$. Fonte: https://www.rotamapas.com.br/distancia-entre-mundo-novo-ms-e-navirai
} 
ABERTI, V. Manual de Historia Oral. In: (Org.) ABERTI, V. Rio de Janeiro: Editora FGV, 3. ed. 2013.

BRASIL. Decreto n. 7.247, de 19 de abril de 1879, do Ministério do Império. Reforma o ensino primário e secundário no município da Corte e o superior em todo o Império. Império do Brasil de 1879 - Parte II, Tomo XLII. Rio de Janeiro: Tipografia Nacional, 1879. p. 196-217. Disponível em: <http://www2.camara.leg.br/legin/fed/de cret/18241899/decreto-7247-19-abril-1879-547933-publicacaooriginal-62862-pe. htm.l>. Acesso em: fev. 2019

BRASIL, RESOLUÇÃO CNE/CP N 1, DE 15 DE MAIO DE 2006. Institui Diretrizes Curriculares Nacionais para o Curso de Graduação em Pedagogia, licenciatura. Disponível em: <http://portal.mec.gov.br/cne/arquivos/pdf/rcp01_06.pdf〉. Acesso em: fev. 2019

BRASIL, Parecer No 05 de 13 de dezembro de 2005. Diretrizes Curriculares Nacionais para o Curso de Pedagogia. Disponível em:

<http://portal.mec.gov.br/cne/arquivos/pdf/rcp01_06.pdf>. Acesso em: fev. 2019

BRASIL, Lei Complementar $n^{\circ} 31$, de 11 de outubro de 1977. Cria o Estado de Mato Grosso do Sul, e dá outras providências. Disponível em:

<http://www.planalto.gov.br/ccivil_03/leis/lcp/Lcp31.htm.pdf>. Acesso em: fev. 2019

BRASIL. Lei 5692, de 11 de agosto de 1971. Estabelece Diretrizes e Bases para a Educação Nacional. Diário Oficial da República Federativa do Brasil, Brasília, DF, 12 agosto. 1971.

BRASIL. MEC. Lei n. 9.394, de 20 de dezembro de 1996. Estabelece as Diretrizes e Bases da Educação Nacional. Brasília: MEC, 1996.

BRAZIL, M. C.; MANCINI, A. P.; MONTEIRO, J. S.; TREVISAN, M. A escola republicana entre ervais e cafezais: cultura material no sul de Mato Grosso (1908-1971). In: FURTADO, A. C.; SÁ, E. F. (Orgs.). História da educação do Centro-Oeste: instituições educativas e fronteiras. Cuiabá, MT: EdUFMT, 2015. 236 p.

CASTANHA, A. P. O Ato Adicional de 1834 e a instrução elementar no Império: descentralização ou centralização? 2007. 558 f. Dissertação (Mestrado em Ciências Humanas) - Universidade Federal de São Carlos - UFSCAR, São Carlos/SP, 2007.

ELIAS, N. Estudos sobre a gênese da profissão naval. In: NEIBURG, F.; WAIZBORT, L. (Org.). Escritos e ensaios. Rio de Janeiro: Jorge Zahar, 2006. p. 69-112.

ELIAS, N. A sociedade da corte: investigação sobre a sociologia da realeza e da aristocracia de corte. Rio de Janeiro: Jorge Zahar Editor, 2001. 
GEBARA, A. Figurações e educação: a escola, os jovens e os professores. In: SARAT, M.; SANTOS, R. (Orgs.). Sobre processos civilizadores - diálogos com Norbert Elias. Dourados, MS: Ed. UFGD, 2012. 330 p.

JOSSO, M-C. Caminhar para si. Tradução de Albino Pozzer, revisão de Maria Helena Menna Barreto Abrahão. Porto Alegre, RS: EDIPUCRS, 2010.

LANDINI, T. S. A Sociologia processual de Norbert Elias. Anais do IX Simpósio Internacional Processo Civilizador. Ponta Grossa, PR, 2005. Anais... Disponível em: <www.uel.br/grupo-estudo/processoscivilizadores/portugues/sitesanais/.../art27.pdf>. Acesso em: 15 maio de 2018.

MEIHY, B. S. C. J. Definindo História Oral e memória. Comunicação apresentada no $1^{\circ}$ Encontro Nacional de História Oral. São Paulo, 19 de abril de 1993. Cadernos CERUn 5 série 2, 1994.

NÓVOA, A. (Org.). Vidas de professores. 2. ed. Porto: Porto Editora, 2000.

PEREIRA, A. M. A disciplina de história da educação e sua apresentação nos módulos de ensino do Projeto Logos II: uma história a ser contada. 2015158 f. Dissertação (mestrado em Educação). UEM. Maringá, Paraná.

RODRIGUEZ, M. V.; OLIVEIRA, R. T. C. História da Escola Normal no estado de Mato Grosso: implantação e consolidação no sul do estado. In: ARAÚJO, J. C. S.; FREITAS, A. G. B.; LOPES, A. P. C. (Org.). As escolas normais no Brasil: do império à República. Campinas, SP: Alínea, 2008.

RODRIGUES, G. T. S. História do Clube de Mães e as origens do Atendimento a criança pequena de Naviraí - (MS) (1974 - 1990). Dissertação (Mestrado em Educação) - Universidade Federal da Grande Dourados - UFGD, Dourados/MS, 2019.

SARAT, M. Educação, memória e gênero: contribuições de Norbert Elias. InterMeio, Campo Grande, MS, v. 17, n. 33, p. 118-139, jan./jun. 2011. Disponível em:

$<$ https://ppgedu.ufms.br/revista-intermeio/>. Acesso em: jan. 2018.

TANURI, L. M. História da formação de professores. Revista Brasileira de Educação. Campinas, n. 14, p. 61-88, maio/jun./jul./ago. 2000.

THOMPSON, E. P. A miséria da teoria ou o planetário de erros: uma crítica ao pensamento de Althusser. Rio de Janeiro: Zahar, 1981.

\section{Entrevistas:}

- João Batista Venâncio. Entrevista concedida a Adriana Horta de Faria. Naviraí/MS, em maio de 2017.

- Maria da Cruz dos Santos. Entrevista concedida a Giseli Tavares de Souza Rodrigues. Naviraí/MS, em fevereiro de 2018. 
ISSN 2237-258X

Recebido em: 03/05/2019

Aprovado em: 05/07/2019 